\title{
Indicated Preterm Birth
}

National Cancer Institute

\section{Source}

National Cancer Institute. Indicated Preterm Birth. NCI Thesaurus. Code C113383.

Preterm birth from 20 weeks to 36 weeks, and 6 days of gestation that is necessitated by the medical condition of the mother or fetus. 